\title{
Fuzzy-based non-bankruptcy trend forecast
}

\author{
Simona Hašková ${ }^{*}$ \\ ${ }^{1}$ The Institute of Technology and Business, School of Expertness and Valuation, Okruzni 517/10, 37001 \\ Ceské Budejovice, Czech Republic
}

\begin{abstract}
Many companies face an economic downturn due to the Covid-19 pandemic outbreak, which makes their future uncertain. The practical aim of the paper is to establish a procedure for an effective prediction of a business tendency to bankrupt in the short-term period. The tool is a three-stage fuzzy model formulated in the theoreticalmethodological part and applied on the real data of an examined company. The model input parameters are objective and subjective measured data between 2008-2020 of a nature affecting the output. The output is an interval of subjectively expected values determining the non-Bankruptcy trend (non-B) of a company. The paper shows advantages of the interval fuzzy approach for bankruptcy prediction and identifies the measure of business safety.
\end{abstract}

Keywords: fuzzy approach, non-bankruptcy index, fuzzy interval prognosis

\section{Introduction}

The Covid-19 pandemic is a health crisis, that has stimulated a serious economic crisis. In the affected economies the basic economic indicators are expected to be lower compared to 2018 until a functional medical treatment, that permanently stabilizes the situation, is found.

In this paper we notice the relationship between the trend of a company to bankrupt/nonbankrupt and the influencing variables of microeconomic and macroeconomic nature that have, to a certain extent, a direct relationship to a bankruptcy threat.

The level of bankruptcy threat results from the crisis future development. A clearer picture is expected in the short time period of 1-3 years and is given by real situation. A current development of basic economic indicators within the first half of 2021 shows an incomplete recovery in most of countries [3]. It is clear that crisis impact, and the way the individual EU states get over, is going to be very uneven. How well and quickly the countries will pull together relies upon external and internal factors that individual economies face ([12] [8]). The pandemic spread and the strictness of containment measures affects the future situation to a certain extend; nevertheless, a great role belongs to economic exposures, preexisting conditions and the policy responses [11].

Regarding the status of the Czech economy the economists and politicians have often discussed the strong dependence on the automotive industry and a strong export focus on Germany. This dependence has always been manifested very clearly during economic crises.

\footnotetext{
${ }^{*}$ Corresponding author: haskovas@post.cz
} 
The last "coronavirus" crises brought a severe decline in the production and sales of cars, automotive components and technologies. For example, Škoda Auto factory, that is understood as the heart of the Czech industry, creates on average for about five percent of GDP and accounts approximately $9 \%$ of exported goods ([1], [14]). The pandemic situation forced the Škoda Auto factory management to stop all lines for several month in 2020.

The paper's aim is to show sensible and trustworthy procedure of the short-term prediction for 2022-2023 of Škoda Auto factory trend to go bankrupt/non-bankrupt. The suitable tool is the fuzzy procedure, that enables to incorporate the human knowledge and expertise. This allows the experts to formulate the inference rules and incorporate specifics of the task into the fuzzy model. To take into account the extreme condition in which the economies currently appear the input variables are expressed as the interval values of occurrence of the historically measured data. The interval output value signals possible trend of the firm to bankrupt/not to bankrupt. We explain why the left limit value performs the important indicator of business safety. This approach fully takes into account the uncertainty of a turbulent environment and offers the external users a more realistic prediction compared to a one-point estimate, which statistical methods standardly offer.

\section{Methodology: The Introduction to Fuzzy Approach}

In the tasks of expert analysis of the vaguely defined systems, the vague terms are usually presented by linguistic variables and their linguistic values (the terms), where the word "linguistic“ is used in the sense of „communicated in natural language “. The relationship between combinations of terms of the input linguistic variables and the output linguistic variable is given by a set of rules [16].

The tool to solve the tasks of vague nature is the fuzzy logic on which the fuzzy approach is based (more in [15]). The fuzzy approach purposefully modifies the assumptions and thus conclusions of the ,principle of extension" of fuzzy logic. The individual fuzzy approach phases are demonstrated in Fig. 1 and are concisely described as follows (for detailed view see [9]):

- The fuzzification phase means that the numerical vector $x=\left(x_{1}, \ldots, x_{n}\right)$ of real input variables is transformed to internal dimensionless input values $u=\left(u_{1}, \ldots, u_{n}\right)$ (mostly expressed as percentage) and as such enters the fuzzy system of the block $K$ (see [7]). In the block $K$ the vector $u$ selects inferential rules relevant to its multi-criteria evaluation. These are the rules of the type $\left(\left(\mathrm{A}_{1 \mathrm{i}}, \ldots, \mathrm{A}_{\mathrm{nj}}\right), \mathrm{B}_{\mathrm{k}}\right) \in P$, in which terms' formalization of the left side of the rule $\mathrm{A}_{1 \mathrm{i}}, \ldots, \mathrm{A}_{\mathrm{nj}}$ all nonzero numbers $\mu_{\underline{A} 1 i}\left(u_{1}\right), \ldots$, $\mu_{\underline{A} n j}\left(u_{n}\right)$ are assigned.

- Moving from the symbolic notation $\left(\left(\mathrm{A}_{1 \mathrm{i}}, \ldots, \mathrm{A}_{\mathrm{nj}}\right), \mathrm{B}_{\mathrm{k}}\right)$ of the selected inference rule to its logic notation dependent on $u$ in the form $\left(\min \left\{\mu_{\underline{A} l i}\left(u_{1}\right), \ldots, \mu_{\underline{A} n j}\left(u_{n}\right)\right\}, \mu_{\underline{B} k}\right)=$ $\left(\mu_{\underline{A^{*}}}(u), \mu_{\underline{B} k}\right)$ we obtain a number $\mu_{\underline{A}^{*}}(u)$ indicating not only the degree of truthfulness that the situation characterized by the vector $u$ actually occurred, but also the degree of significance of the term $\mathrm{B}_{\mathrm{k}}$ in the multi-criteria evaluation of the vector $u$.

- $\mu_{\underline{B} k}: Y \rightarrow\langle 0,1\rangle$ is the standard membership function of the elements $y \in Y$ to the fuzzy set $\underline{B}_{k}$. On the other hand, $\mu_{\underline{B} k}{ }^{*}: Y \rightarrow\langle 0,1\rangle$ in the form $\mu_{\underline{B} k}(y)=\min \left\{\mu_{\underline{A}^{*}}(u)\right.$, $\left.\mu_{\underline{B} k}(y)\right\}$ limits from above the function $\mu_{\underline{B} k}$ by means of the number $\mu_{\underline{A^{*}}}(x)$.

- The components of the fuzzy system of the block $K$ will then be the elements of the set $P_{u}=\left\{\mathrm{B}_{\mathrm{k}}: \exists y:\left(\min \left\{\mu_{\underline{A}^{*}}(u), \mu_{\underline{B} k}(y)\right\}>0\right),\left(\left(\mathrm{A}_{1 \mathrm{i}}, \ldots, \mathrm{A}_{\mathrm{nj}}\right), \mathrm{B}_{\mathrm{k}}\right) \in P, y \in Y\right\}$. These are the partial intermediate results by aggregation (logical sum) of which we obtain the formalized term $\underline{B}_{a g g}=\left\{\left(y, \mu_{\text {agg }}(y)\right): y \in Y\right\}$ on $Y$, for which it applies (1)

$$
\mu_{\text {agg }}(y)=\max \left\{\min \left\{\mu_{\underline{A}^{*}}(u), \mu_{\underline{B} k}(y)\right\}:\left(\left(A_{1 i}, \ldots, A_{n j}\right), B_{k}\right) \in P, y \in Y\right\}
$$


- The defuzzification phase is the last step to obtain the output value $y_{x}$ of the multicriteria model of an alternative $\left(a_{1}, \ldots, a_{c}\right) \in A$ as the mean value of the elements $y \in \underline{B}_{a g g}$ weighted by the values $\mu_{a g g}(y)$ of their significance - see (2). Therefore

$$
y_{x}=\int y \cdot \mu_{a g g}(y) d y / \int \mu_{a g g}(y) d y
$$

where $\int$ is the symbol of a definite integral over the universe $Y$ - more in detail in [6] and [2].

The process of the multi-criteria assessment of a short time prediction of the trend of the Czech company Škoda Auto factory not to go bankrupt/not to go bunkrupt is demonstrated in other sections.

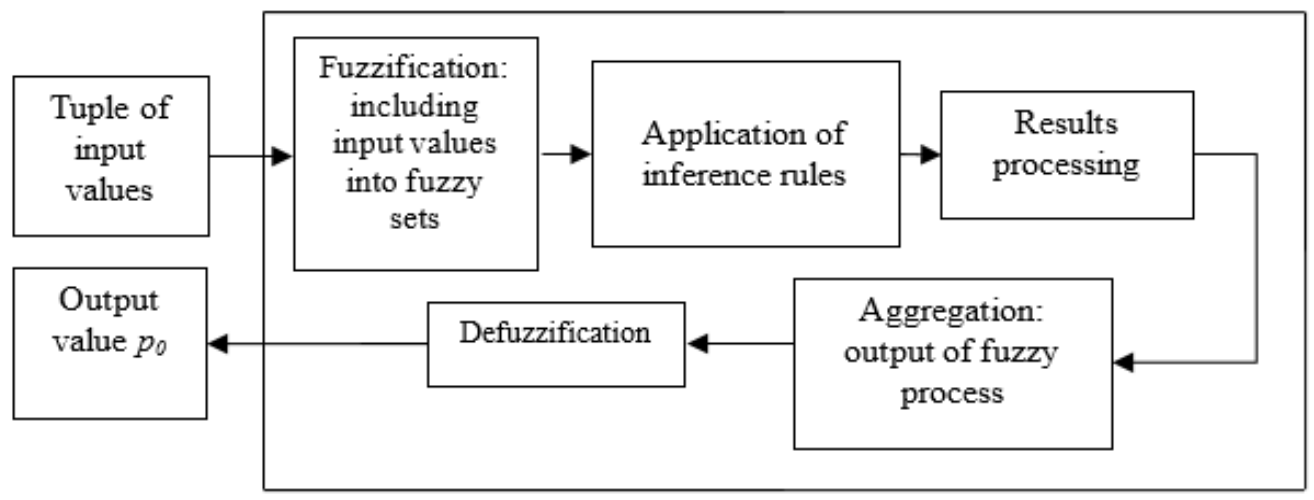

Fig. 1. Schematic representation of the multicriteria problem solving process within the fuzzy approach Source: Author's own processing.

\section{Application - Introduction to the Problem}

The strong dependence of the Czech economy on the automotive industry with a strong export focus on Germany have often been critically discussed by economists and politicians. This dependence had clearly manifesed itself during economic recession as the data of car production volume in Tab. 1 show.

Table 1 The passenger cars' production in the Czech Republic

\begin{tabular}{|l|c|c|c|c|c|c|c|c|c|c|c|c|c|}
\hline Year & $\mathbf{2 0 0 8}$ & $\mathbf{2 0 0 9}$ & $\mathbf{2 0 1 0}$ & $\mathbf{2 0 1 1}$ & $\mathbf{2 0 1 2}$ & $\mathbf{2 0 1 3}$ & $\mathbf{2 0 1 4}$ & $\mathbf{2 0 1 5}$ & $\mathbf{2 0 1 6}$ & $\mathbf{2 0 1 7}$ & $\mathbf{2 0 1 8}$ & $\mathbf{2 0 1 9}$ & $\mathbf{2 0 2 0}$ \\
\hline $\begin{array}{l}\text { Passenger car } \\
\text { production (ths. } \\
\text { units) }\end{array}$ & 934 & 976 & 1070 & 1192 & 1172 & 1128 & 1247 & 1298 & 1344 & 1414 & 1437 & 1428 & 1005 \\
\hline
\end{tabular}

Source: [10], [14] / author's own processing.

The data in Tab. 1 show that in the year 2020 the Czech (and also German) automotive sector returned to the values of 2009 crisis year. The coronavirus outspread at the beginning of 2020 brought a rapid decline in the production and sales of cars, automotive components, and technologies. The reasons are obvious: the whole economy decline accompanied by uncertainty on the demand side, the cessation of investment and renewal of vehicle fleets, and last but not least the closure of car showrooms and car bazaars. 
At this point we should remind ourselves that the automotive sector had already been decreasing for some years before Covid-19 outbreak. It was mainly caused by the decline in demand in China; the markets of North America and Europe were roughly stagnant. The drop in production and sale was also caused due to the transition to the electric car production as some factories were modified to produce electric cars and their capacity decreased. This transition goes hand in hand with the additional costs that increase the price of cars ([10], [13].

\subsection{Assumptions and Data of the Fuzzy Predictive Model}

The formulation of the fuzzy model of prediction of the non-Bankrupt trend (non-B) has the following specifics:

- We can specify indicators affecting the target variable (non-B) - these are historically measured data of influencing input variables.

- The trend of influencing input variables can be used for the one-point prediction purposes only if an economy is not at the state of an extreme, which deviates to one or the other side (extreme growth/decline) from the "normal" (expected) framework (in terms of quantification of the decline, growth or stagnation). Its prediction is justified by the development of the historical part of influencing input values on which a target output vaguely depends - under these circumstances the fuzzy procedure was succesfully applied e.g. in [8].

- Under extreme conditions and/or the high uncertainty of input data the prognosis relies on the possible values of input variables specified by intervals; from this it is obvious that the prediction outcome is presented in the form of the interval of possible values.

Tab. 2 shows the developement of the input variables between $2008-2020$ affecting the target variable non- $\mathrm{B}$, which are $\Delta \mathrm{GDP}_{\mathrm{G}} \%$ (a yearly change in Germany's gross domestic product), $\triangle \mathrm{AP}_{\mathrm{CZ}} \%$ (a yearly change in the Czech cars' production) and Z-score (a bankruptcy criterium Z-score based on a modified version of the Taffler's model). From the viewpoint of external and internal interest groups these entry data perform results, for which the highest possible value is desirable.

Table 2 Basic macroeconomic input data for fuzzy model of non-B prediction

\begin{tabular}{|c|c|c|c|c|c|c|c|c|c|c|c|c|c|}
\hline Variable/Year & $\mathbf{2 0 0 8}$ & $\mathbf{2 0 0 9}$ & $\mathbf{2 0 1 0}$ & $\mathbf{2 0 1 1}$ & $\mathbf{2 0 1 2}$ & $\mathbf{2 0 1 3}$ & $\mathbf{2 0 1 4}$ & $\mathbf{2 0 1 5}$ & $\mathbf{2 0 1 6}$ & $\mathbf{2 0 1 7}$ & $\mathbf{2 0 1 8}$ & $\mathbf{2 0 1 9}$ & $\mathbf{2 0 2 0}$ \\
\hline $\mathrm{GDP}_{\mathrm{G}} \%$ & 0,8 & $-5,7$ & 4,2 & 3,9 & 0,4 & 0,4 & 2,2 & 1,7 & 2,2 & 2,5 & 1,5 & 0,6 & $-5,8$ \\
\hline $\mathrm{AP}_{\mathrm{CZ}} \%$ & 1,4 & 4,5 & 9,5 & 11,5 & $-1,7$ & $-3,7$ & 10,5 & 4,2 & 3,5 & 5,2 & 1,7 & $-0,7$ & $-29,6$ \\
\hline $\mathrm{Z}$-score & 1,1 & 0,92 & 1,06 & 1,1 & 1 & 1,1 & 0,9 & 1,2 & 1,5 & 1,6 & 1,3 & 1,1 & 0,9 \\
\hline
\end{tabular}

Source: [4], [14] / author's own processing.

From Tab. 2 we see two significant slowdowns (2008/2009 and 2020). The 2008/2009 downturn is primarily caused by the financial crisis 2008 followed by the economic crises; the second slowdown is due to the Covid-19 pandemic outbreak.

The Czech economy was not affected by the global 2008 financial crisis; it was rather hit by the global economic crisis, which followed and which was mainly a consequence of a sharp decline in foreign demand (a GDP yearly change in the Czech republic in 2009 was 4,7 $\%$ / the yearly drop of GDP of eurozone in 2009 was $-4,5 \%$ ). The current Covid-19 crisis has been a major economic recession, which significantly affected almost all economies in the world (the 2020 yearly drop in GDP of the Czech republic was 5,8\%, in eurozone countries it was $-6,5 \%)$. 
Needless to say that any one-point economic prognosis does not have much informative value as enormous uncertainty is still presented [5]. The coronavirus spread and precautionary measures have not disappeared. On the other hand, we cannot ignore that the population immunization is growing. Furthermore, the development of new drugs and advanced vaccines indicate a real possibility of a positive reversal. The economy release phases followed by restrictions' alleviation were accompanied by growing demand for goods and services. Moreover, the abnormal rise in the amount of private savings made during the strict pandemic measures (although the level of savings is very uneven in the population) makes many economists believe that economies embark on a path of growth in demand and supply, and thus in the growth of GDP in the forcomming period.

\subsection{Procedures and Results}

A direct prediction of a non-bankrupcy trend from the historical series of values $\mathrm{GDP}_{\mathrm{G}}, \mathrm{AP}_{\mathrm{CZ}}$ and Z-score is not possible. At this stage, the state of affairs described above and the opinion of experts is a major specificity of the fuzzy model formulation, i.e., determination of the model structure and formulation of inference rules.

Regarding the uncertainty and the aforementioned arguments for a positive medical and economic development we will consider the influencing variables within the interval limits, in which the "worst" data are non-negative lowest values, or respectively the "best" data are the highest values of the period 2008-2020 $\left(\mathrm{GDP}_{\mathrm{G}} \% \in\langle 0,4 ; 4,2\rangle, \mathrm{AP}_{\mathrm{CZ}} \% \in\langle 1,4 ; 11,5\rangle, \mathrm{Z}-\right.$ score $\in\langle 0,9,1,6\rangle)$ - see Tab. 2.

The model works with the dimensionless values $(\%) u_{\text {Z-score, }} u_{\mathrm{AP}} \mathrm{CZ}, u_{\mathrm{GDP}} \mathrm{G}$ of input universes $U_{\mathrm{Zscore}}, U_{\mathrm{AP} \_\mathrm{CZ}}, U_{\mathrm{GDP} \_\mathrm{G}}$, or respectively with dimensionless value (\%) $y$ of output universe $Y_{\mathrm{BT}}$. The dimensionless input values are obtained by converting the given basal input interval values $x_{\text {Z-score }} \in\langle 0,9 ; 1,6\rangle, x_{\mathrm{AP}_{-} \mathrm{CZ}} \in\langle 1,4 ; 11,5\rangle, x_{\mathrm{GDP}_{-} \mathrm{G}} \in\langle 0,4 ; 4,2\rangle$ of the respective input linguistic variables into interval $\langle 0,100\rangle$, where the $100 \%$ signals zero threat to bankrupcy; analogically, the left extreme indicates a definite bankrupt.

The fuzzy system in block $K$ includes numerical vectors in \% $\left(G D P_{G}, A P_{C Z}, Z\right.$-score $)$, $G D P_{G} \in\langle 10,100\rangle, A P_{C Z} \in\langle 12,100\rangle, Z$-score $\in\langle 56,100\rangle$ of the triple of input linguistic variables $\mathrm{GDP}_{\mathrm{G}}, \mathrm{AP}_{\mathrm{CZ}}$ and $\mathrm{Z}$-score with terms $\underline{L} \mathrm{i}, \underline{M} \underline{\mathrm{i}}_{\mathrm{i}}$ and $\underline{H}_{\mathrm{i}}, \mathrm{i}=\mathrm{gdp}_{\mathrm{g}}, \operatorname{ap}_{\mathrm{cz}}, \mathrm{Z}_{\text {-score }}(\underline{L}-\operatorname{low}, \underline{M}$ - middle, $\underline{H}$ - high).

Let us suppose that fuzzification tables for linguistic input variables are symmetric and identical except for the subscripts (i.e., for all $\mathrm{i}=\mathrm{gdp}$, ap $\mathrm{p}_{\mathrm{cz}}, \mathrm{z}_{\mathrm{score}}$ it applies: $a_{\mathrm{i}}=20, b_{\mathrm{i}}=40$, $\left.c_{\mathrm{i}}=60, d_{\mathrm{i}}=80\right)$, which applies for the output linguistic variable non-B as well, see Table 3.

Table 3 Fuzzification table valid for $\mathrm{i}=\mathrm{gdp}$, ap $\mathrm{p}_{\mathrm{cz}}, \mathrm{z}_{\text {score }}$

\begin{tabular}{|c|c|c|c|c|c|}
\hline Interval & $\boldsymbol{u}_{\mathbf{i}}<\mathbf{2 0}$ & $\mathbf{2 0} \leq \boldsymbol{u}_{\mathbf{i}}<\mathbf{4 0}$ & $\mathbf{4 0} \leq \boldsymbol{u}_{\mathbf{i}}<\mathbf{6 0}$ & $\mathbf{6 0} \leq \boldsymbol{u}_{\mathbf{i}}<\mathbf{8 0}$ & $\boldsymbol{u}_{\mathbf{i}} \geq \mathbf{8 0}$ \\
\hline$\underline{\boldsymbol{L}}_{\mathbf{i}}$ & 1 & $\left(40-u_{\mathrm{i}}\right) / 20$ & 0 & 0 & 0 \\
\hline $\boldsymbol{M}_{\mathbf{i}}$ & 0 & $\left(u_{\mathrm{i}}-20\right) / 20$ & 1 & $\left(80-u_{\mathrm{i}}\right) / 20$ & 0 \\
\hline$\underline{\boldsymbol{H}}_{\mathbf{i}}$ & 0 & 0 & 0 & $\left(u_{\mathrm{i}}-60\right) / 20$ & 1 \\
\hline
\end{tabular}

Source: authors' own processing.

The following fuzzy procedure in block $K$ enables us to calculate a number $y \in\langle 0,100\rangle$ of the output linguistic variable of a non-Bankrupt trend (non-B) taking into account the setting of the terms $\underline{L}, \underline{M}$ and $\underline{H}$. The set of inference rules of the type (( $\left.\underline{T}_{\mathrm{gdp} \_\mathrm{g}}, \underline{T}_{\mathrm{ap} \_\mathrm{c} z}, \underline{T} \mathrm{Z}_{\mathrm{Z} \text {-score }}\right)$, $\underline{T}), \underline{T_{\mathrm{i}}} \in\left\{\underline{L_{\mathrm{i}}}, \underline{M_{\mathrm{i}}}, \underline{H_{\mathrm{i}}}\right\}, \underline{T} \in\{\underline{L}, \underline{M}, \underline{H}\}$ has 27 elements formed by the strategies of the predominant element. It assigns to the given left side the very term $\underline{T}$, which predominates on the left side. If there is no such term, the term $\underline{M}$ is assigned. 
For the recalculated vector $\left(u_{1}, u_{2}, u_{3}\right)$ it holds: $u_{1}=g d p_{g}, u_{2}=a p_{c z}$ and $u_{3}=z_{\text {score. }}$. To obtain the outputs $y_{\min }$ and $y_{\max }$, the interval values combination $\left(u_{1 \min }, u_{2 \min }, u_{3 \min }\right)$ for $y_{\min }$ and $\left(u_{1 \max }, u_{2 \max }, u_{3 \max }\right)$ for $y_{\max }$ is processed as follows:

- $\quad h\left(u_{1 \min }\right)=h(10)=\left\{\underline{L}_{\text {gdp } \_g}\right\}, h\left(u_{2 \min }\right)=h(12)=\left\{\underline{L}_{\text {ap_cz }}\right\}, h\left(u_{3 \min }\right)=h(56)=\left\{\underline{M}_{Z \text {-score }}\right\}, H=$ $\left\{\left(\underline{L}_{\text {gdp } \_g}, \underline{L}_{\text {ap_cz }}, \underline{M} \underline{Z}_{\text {-score }}\right)\right\}$. The triad $\left(\underline{L}_{\text {gdp_g }}, \underline{L_{\text {ap }} \mathrm{cz},}, \underline{M} \underline{M}_{\text {-score }}\right)$ of the input fuzzy sets of the projection $F$ assigns the output fuzzy set $\underline{H}$ according to the already mentioned strategy of the predominant element. Therefore, $\mathrm{M}_{\underline{M}}=\mathrm{M}_{\underline{H}}=0, \mathrm{M}_{\underline{L}}=\mu_{A G G}(y)=\mu_{\underline{L}}(y)$.

For the value $y_{\min }$ it holds: $y_{\min }=\int y \cdot \mu_{\underline{a g g}}(\bar{y}) \mathrm{d} y / \int \mu_{\underline{a g g}}(y) \mathrm{d} y=30 / 2=\mathbf{1 5} \mathbf{\%}$.

- $\quad h\left(u_{1 \max }\right)=h(100)=\left\{\underline{H}_{\text {gdp_g }}\right\}, h\left(u_{2 \max }\right)=h(100)=\left\{\underline{H}_{\text {ap_cz }}\right\}, h\left(u_{3 \max }\right)=h(100)=\left\{\underline{H}_{Z}\right.$-score $\}$, $H=\left\{\left(\underline{H}_{\text {gdp } \_g}, \underline{H}_{\text {ap_cz }}, \underline{H}_{\text {Z-score }}\right)\right\}, \mathrm{M}_{\underline{L}}=\mathrm{M}_{\underline{M}}=0, \mathrm{M}_{\underline{H}}=\max \{\{\min \{1,1,1\}\}\}=1$.

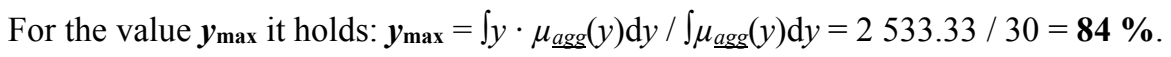

- $\quad$ The average interval fuzzy value $y_{u}=(15+84) / 2=\mathbf{4 9 , 5} \%$.

\section{Results Discussion and Practical Usage}

The fuzzy procedure of deffuzification step (see Fig. 1) provided us with the output of the fuzzy interval $y(\%)=\langle 15 ; 49,5 ; 84\rangle$ expressing the tendency of the company not to get bankrupt in the short term period 2022-2023. According to the model results, the non- $\mathrm{B}=y_{u}$ $=49,5 \%$, i. e., the average susceptibility of Škoda Auto factoty not to bankrupt is medium.

At this point it is necessary to take into account the facts regarding the positive trend in retreat of Covid-19 pandemy, the positive trend in indicators' development within the first half of the year $2021\left(\mathrm{GDP}_{\mathrm{G}} \%=3,6, \mathrm{AP}_{\mathrm{CZ}} \%=24,7\right)$ and the values of $\mathrm{Z}$-score $>0,3$ within the period 2008-2020 (the Taffler's model has excluded an imminent threat of bankruptcy of Škoda Auto factory across the reference period). This entitles us to argue that the threat of bankruptcy in the next two years is below average; the fuzzy values of non-bankrupcy trend are therefore $y(\%)=\langle 49,5 ; 84\rangle$ with the non-B $=y_{u}=67 \%$ as the average indicator of nonbankrupcy.

Given the fact that the left extreme $y_{\min }=49,5$ is the bottom limit of possible (expected) values, which will not be likely lower (with the $70 \%$ probability) in the next two years' period, the value $y_{\min }$ can be interpreted as a measure of business safety from the viewpoint of the bankruptcy evaluators.

\section{Conclusion}

The aim of the paper was to present a general fuzzy algorithm formulated within the Zadeh's fuzzy approach for solving an economic short-term prediction under conditions of external uncertainty (relating to the data entering the model) and internal uncertainty (related to the algorithmic model). Such a procedure offers a short-time period prediction more than equivalent to an alternative statistical prognosis.

The presented fuzzy algorithm builds its core procedures on one of the important concepts of fuzzy logic, which is the "extension principle", at the level of linguistic variables and their terms within which the problem is solved. The algorithm was utilized to estimate the nonbankrupcy trend (non-B) of the Škoda Auto factory within an interval of possible values.

Under „normal“, i.e., an expected behaviour of economy, the entry data are partial components of the historical development of the indicators that directly and, to a certain extent expectidely, influence the behaviour of a target output and its prediction (the influencing indicators here are a change in German gross domestic product, a change in the 
Czech cars' production and a bankruptcy criterium Z-score based on a modified version of the Taffler's model, the target indicator is a non-bakrupcy index (non-B) of the Škoda Auto factory). Due to the Covid-19 outbreak such a direct procedure is excluded.

Instead, the possible development of influencing input variables is taken into account in the form of interval values capturing the extreme data of the downturn and growth within the monitored period 2008-2020. The input data are used in the fuzzy model formulation phase, within which an expert, through the interventions in the structure of the model and the formulation of inference rules, takes into account one's own knowledge and experience. The own process of solving the problem is mechanical and independent of the human factor.

The fuzzy process consists of five steps, which are fuzzification, application of inference rules, further processing of intermediate results, aggregation and defuzzification. The here formulated fuzzification table makes the solution more transparent and easier. Regarding the inference rules in the function of tools for partial transformations of inputs to an output, only one of the total number of 27 was used: $((\underline{L}, \underline{L}, \underline{M}), \underline{L})$. The right-hand side of the rule corresponds with the predominant element strategy in formulation of the system of inferential rules.

The result of the solution at the level of terms of the linguistic variable non-B $\%$ was an interval of possible values $y(\%)=\langle 15 ; 49,5 ; 84\rangle$ expressing the tendency of the company not to get bankrupt in the short term period 2022-2023. Other objective facts had to be taken into account when evaluating the results and interpreting them: the positive trend in retreat of Covid-19 pandemy, the positive trend in $\mathrm{GDP}_{\mathrm{G}}$ and $\mathrm{AP}_{\mathrm{CZ}}$ indicator development within the first half of the year 2021 and the values of Z-score > 0,3 within the period 2008-2020 excluding an imminent threat of bankruptcy of Škoda Auto factory. This entitled us to argue that the threat of bankruptcy of Škoda Auto factory in 2022-2023 is below average: it can be expected in the interval of possible values $y(\%)=\langle 49,5 ; 84\rangle$ with the non-B $=y_{u}=67 \%$ as the average indicator of non-bankrupcy. The results can be interpreted as a measure of business safety from the viewpoint of the bankruptcy evaluators, which is an indicator that can be widely utilized in practice.

\section{References}

1. F. Aliu, D. Pavelkova, B. Dehning, Portfolio risk-return analysis: The case of the automotive industry in the Czech Republic. Journal of International Studies (2017)

2. L. Běhounek, P. Cintula, From fuzzy logic to fuzzy mathematics: A methodological manifesto. Fuzzy Sets and Systems, 157(5), 642-646 (2006)

3. Eurostat, Your key to European statistics - euro indicators.[online], Available at: https://ec.europa.eu/eurostat/news/euro-indicators (2021)

4. Eurostat, Germany: Real GDP growth rate - volume. [online], Available at: https://ec.europa.eu/eurostat/databrowser/view/tec00115/default/table?lang=enStatista (2020)

5. A. Evgenidis, S. Papadamou, C. Siriopoulos, The yield spread's ability to forecast economic activity: What have we learned after 30 years of studies?. Journal of Business Research, 106, 221-232 (2020)

6. M. Grabisch, The application of fuzzy integrals in multicriteria decision making. European Journal of Operational Research, 89(3), 445-456 (1996)

7. S. Hašková, Estimation of Long-Term Projects in Terms of Uncertainty of Inputs. 38TH INTERNATIONAL CONFERENCE ON MATHEMATICAL METHODS IN 
ECONOMICS (MME 2020). (Eds.). Kapouek, S. \& Vranova, H., (pp. 154-159), Brno, CZECH REPUBLIC (2020)

8. S. Hašková, S, Fuzzy approach to short-term youth unemployment forecast. In SHS Web of Conferences, 73, 01007. EDP Sciences (2020)

9. S. Hašková, P. Fiala, A fuzzy approach for the estimation of foreign investment risk based on values of rating indices. Risk Management, 21(3), 183-199 (2019)

10. International Organization of Motor Vehicle Manufacturers [online], Available at: https://www.oica.net/category/production-statistics/2019-statistics/ (2021)

11. R. M. del Rio-Chanona, P. Mealy, A. Pichler, F. Lafond, D. Farmer, Supply and demand shocks in the COVID-19 pandemic: An industry and occupation perspective. ArXiv preprint arXiv:2004.06759 (2020)

12. T. A. Skvortsova, T. A. Pasikova, L. N. Vereshchagina, A. N. Pozdnishov, A. V. Sukhovenko, The problem of bankruptcy of business entities as a consequence of the COVID-19 pandemic (2020)

13. M. Srivastava, L. Tyll, The effect of industry-specific networking behaviour on the internationalization performance of Czech SMEs. European Business Review (2020)

14. Škoda, Výroční zprávy [online], Available at: https://www.skodastoryboard.com/cs/vyrocni-zpravy/ (2021)

15. L. A. Zadeh, Fuzzy logic and approximate reasoning. Synthese, 30(3-4), 407-428 (1975)

16. L. A. Zadeh, K. S. Fu, K. Tanaka. (Eds.). Fuzzy sets and their applications to cognitive and decision processes: Proceedings of the us-japan seminar on fuzzy sets and their applications, held at the university of california, berkeley, california, july 1-4, 1974. Academic press (2014) 